\title{
Cartografia da produção do cuidado na Estratégia Saúde da Família
}

\author{
Cartography of care production in the Family Health Strategy \\ Cartografía de la producción de la atención en la Estrategia de Salud Familiar
}

\author{
Maria Rocineide Ferreira da Silva \\ ORCID: https://orcid.org/0000-0002-6086-6901 \\ Universidade Estadual do Ceará, Brasil \\ E-mail: rocineideferreira@gmail.com \\ José Ivo dos Santos Pedrosa \\ ORCID: https://orcid.org/0000-0002-5416-2860 \\ Universidade Federal do Piauí, Brasil \\ E-mail: jivopedrosa@gmail.com \\ Olga Maria de Alencar \\ ORCID: https://orcid.org/0000-0003-2477-7503 \\ Universidade Estadual do Ceará, Brasil \\ E-mail: olgaalencar17@gmail.com \\ Mirna Neyara Alexandre de Sá Barreto Marinho \\ ORCID: https://orcid.org/0000-0002-5853-6532 \\ Universidade Estadual do Ceará, Brasil \\ E-mail: mirna.neyara@gmail.com \\ Thayza Miranda Pereira \\ ORCID: https://orcid.org/0000-0001-6979-947X \\ Universidade Federal do Tocantins, Brasil \\ E-mail: thayzinhamiranda@gmail.com \\ Ricardo José Soares Pontes \\ ORCID: https://orcid.org/0000-0002-8976-4562 \\ Universidade Federal do Ceará, Brasil \\ E-mail: rjpontes@ @ortalnet.com.br
}

\begin{abstract}
Resumo
Objetivou-se realizar a cartografia dos elementos da produção de cuidado que se fazem presentes na Estratégia Saúde da Família. Estudo qualitativo com abordagem da cartografia realizado em uma unidade de saúde da família, com população de 7.881 famílias, em Fortaleza-CE, Brasil. Participaram da pesquisa doze trabalhadores e quatro usuários do serviço, os quais compartilharam das oficinas de produção de dados. A cartografia apresentou relevos em multiplicidades pela polifonia expressa nas relações comunicacionais e a polissemia de sentidos no cotidiano dos serviços. Observou-se a existência de espaços, cuja produção do cuidado se encontra cristalizada, com discurso da falta, que é capaz de imobilizar sujeitos (trabalhadores e usuários). As linhas de fuga foram produzidas e davam brechas para apontar caminhos desejados e possíveis. A cartografia apresentou relevos em multiplicidades, pela polifonia expressa nas vozes dos trabalhadores e usuários. Evidenciou-se uma polissemia de sentidos que, enquanto forças, podem desterritorializar-se para garantir a produção do cuidado na ESF, bem como práticas de cuidado comprometidas com a produção da saúde.
\end{abstract}

Palavras-chave: Saúde; Atenção primária à saúde; Estratégia saúde da família.

\begin{abstract}
The objective was to map the elements of care production present in the Family Health Strategy. It was a study carried out in a Family Health Unit, with a population of 7,881 families, in Fortaleza-CE, Brazil. Research population comprised twelve health workers and four service users, who shared data production workshops. Cartography demonstrated emphasis in multiplicities due to the polyphony expressed in communicational relations and the polysemy in the service routine. It was observed the existence of spaces, whose care production is crystallized, with a discourse of shortage, which can immobilize subjects (workers and users). Escape lines were produced and provided loopholes to indicate desired and possible paths. It is understood that through the awakening of the vibrating body with the potential to affect meetings the production of new concepts and, consequently, care practices committed to health production will occur.
\end{abstract}

Keywords: Health; Primary health care; Family health strategy.

\section{Resumen}

El objetivo fue realizar el mapeo de los elementos de producción asistencial presentes en la Estrategia de Salud Familiar. Estudio realizado en unidad de salud familiar, con población de 7,881 familias, en Fortaleza-CE, Brasil. Participaron de la investigación los trabajadores y usuarios del servicio, quienes compartieron los talleres de 
producción de datos. La cartografía mostró alivio en sus multiplicidades, debido a la polifonía expresada y la polisemia de significados. Se observó la existencia de espacios, donde se cristalizan la producción de cuidados, con discurso de falta, que permite inmovilizar a los sujetos (trabajadores y usuarios). Se produjeron líneas de escape y se proporcionaron lagunas para señalar las rutas deseadas y posibles. Es a través del despertar del cuerpo vibratorio que tiene el potencial de afectar las reuniones en las que se producirán nuevos conceptos y, en consecuencia, prácticas de atención comprometidas con la producción de salud.

Palabras clave: Salud; Atención primaria de salud; Estrategia de salud familiar.

\section{Introdução}

Vivenciado como experiência de Atenção Primária em Saúde (APS), em diversos municípios do Brasil, em 1994, o Programa Saúde da Família (PSF) foi institucionalizado na agenda governamental, apresentando um modelo assistencial com propósito de oferecer prioridade, além da assistência individual, ações de proteção e promoção à saúde (Brasil, 2017; Arruda \& Bosi, 2017).

As condições para surgimento desse programa ocorreram no âmbito de uma série de transformações sucedidas desde a reforma sanitária brasileira, movimento que ganhou corpo no período da ditadura militar no Brasil, formado por movimentos sociais/populares, acadêmicos e de trabalhadores, que ficou reconhecido pelo caráter ideológico, com prática política que confrontava teoricamente o modelo preventivista neoliberal, sobretudo, com a versão racionalizadora proposta pelo Estado. Pautava-se pela reformulação do objeto da saúde que, desde as bases do materialismo histórico, pretendia superar o biologicismo nas formas de lidar com a saúde e a doença (Lemos, 2018; Giovanella et al., 2021).

O PSF nasceu com a aposta no vínculo como potencialidade para o cuidado, na adscrição da clientela ao território compreendido como espaço de produção e reprodução da vida, observado não apenas na dimensão geográfica física, como também com implicações culturais, sociais, afetivas e subjetivas. O modelo proposto reconheceu a possibilidade da comunidade em promover mudanças cotidianas, no sentido da produção da qualidade de vida e dos diversos significados que os processos de viver e adoecer têm para uma dada população (Silva, Silveira, Pontes, \& Vieira, 2015).

Com tais características, o PSF não expressa somente uma proposta macropolítica na forma de um programa governamental, no âmbito da política pública de saúde, mas contempla, principalmente, relações que ocorrem na dimensão da micropolítica, possibilitando espaço para o instituinte (Silva et al., 2015).

Nesse âmbito, a aposta se encontra na produção desejante de sujeitos que se deixam afetar pela vida que, muitas vezes, está distante de quem planeja a política, que guardam a possibilidade de provocarem transformações nos espaços onde estão inseridos, uma vez que atuam de modo singular (Agonigi, Carvalho, Freire, \& Gonçalves, 2018) e constroem a cogestão dos processos (quando, além de gestores e trabalhadores, a população também fala e assume responsabilidades).

É no espaço da micropolítica e no processo de produção desejante que acontece o encontro desses sujeitos, no qual são construídos graus de implicação com a aposta do PSF (que, posteriormente, passa a ser denominado Estratégia Saúde da Família), contribuindo para o que pode ou não ocorrer. Este plano de relações que se situa no terreno do desejo é o campo dos agenciamentos, em que circulam possibilidades de produção do cuidado nos territórios (Guattari \& Rolnik, 2011; Ferla, 2017; Santos \& Ceccon, 2021).

Historicamente, no processo de institucionalização das políticas, este aspecto tem sido desconsiderado e não reconhecido, fortalecendo a dualidade existente entre a ação emancipatória, em que o poder da população fica evidenciado, à medida que esta se organiza, formula e aprova uma Constituição Cidadã e ação de regulação tecnocrática evidente, na implantação desse processo, condicionado pelo caráter fortemente neoliberal dos governos na América Latina e pelo permanente embate entre os interesses das camadas populares e das elites locais.

As leituras e vivências em locais onde a Estratégia Saúde da Família (ESF) se revelou capaz de se coproduzir, suscitaram alguns questionamentos: o que se passa na configuração dos territórios onde a produção desejante é potencializada 
ou levada a se cristalizar em uma massa amorfa e sem vida? O que faz com que o trabalhador faça de sua inserção na ESF uma verdadeira produção do cuidado e, em outros espaços, isso se converta apenas em um trabalho burocratizado?

É necessário lançar mão de dispositivos que despertem o desejo e façam, em meio à produção capitalística da subjetividade, surgir algo da produção desejante desses coletivos, entendendo produção capitalística como a essência do lucro, que não se reduz ao campo da mais valia econômica, por se encontrar também na tomada de poder da subjetividade. O desejo é aqui entendido como força propulsora e propositiva do agir em saúde, do trabalho vivo em ato, sendo, ao mesmo tempo, produção material, de sentidos presentes na realidade (Guattari \& Rolnik, 2011).

A cartografia proposta por autores que trabalham com as questões que focalizam os espaços de produção local, a partir dos fluxos resultantes e das relações que se cruzam e entrecruzam nesse cotidiano, provoca-nos adentrar nesse mundo de multiplicidades (Ferla, 2017).

Para iniciar essa cartografia, é preciso, em primeiro lugar, ter clareza de que o Sistema Único de Saúde (SUS) é constituído por possibilidades políticas que ocorrem no espaço da dualidade entre o pretendido e o feito, ou seja, por um lado; territórios marcados pelas práticas curativas e prescritivas, clínica centrada nos aspectos mecanicistas e biologicistas, trabalho burocratizado, organizado sob normas rígidas dificilmente passíveis de questionamento e pouco relacionais; por outro lado, observam-se movimentos que seguem outras orientações, seja o vínculo entre trabalhadores e destes com usuários, pautados por práticas acolhedoras, seja a produção de subjetividades presentes em cada processo e os modos de subjetivação (Santos, Mishima, \& Merhy, 2018).

No encontro entre essas condições do SUS e a produção de subjetividades que se desenrola nesses espaços, define-se o objetivo do artigo de realizar a cartografia da ESF, considerando os elementos da produção do cuidado, identificando possibilidades para produção do cuidado integral.

\section{Metodologia}

Adotamos a cartografia como método de pesquisa, pois se propõe a captar elementos presentes na dinâmica do território formal e acompanhar processos de produção de subjetividades nos territórios existenciais, que constituem simultaneamente a realização da própria pesquisa (Deleuze \& Guattari, 2017; Rolnik, 1987), caracterizando uma pesquisa intervenção/ação de natureza qualitativa. A cartografia proposta por Gilles Deleuze e Félix Guattari como um método investigativo refere-se ao acompanhamento de um processo, e não a representação de um objeto. Em linhas gerais, trata-se sempre de investigar um processo de produção, que não busca um método linear para atingir um fim. A cartografia é sempre um método ad hoc (Silva \& Rojas, 2016).

Com a cartografia, podemos perceber os fluxos e as linhas que se estabelecem no território existencial, a partir de uma perspectiva rizomática, com suporte na ação dos sujeitos que produzem conexões entre si e com o território externo.

A produção dos dados da pesquisa aconteceu em quatro oficinas, tendo como temas: formação do grupo e negociação dos objetivos da pesquisa; política de organização do serviço; relações na unidade de saúde e produção do cuidado; e gestão e participação social, que funcionaram como dispositivos, estabelecendo diálogos, conversações sobre esses temas e vivências cotidianas. Pensar o dispositivo é pensar efeitos, é se aliar a ação/criação, é montar situações que articulem elementos heterogêneos acionando modos de funcionamento que produzirão certos efeitos (Rolnik, 1987, p.105).

As oficinas, dispositivos de criação e criatividade, nos quais os sujeitos puderam produzir pinturas, fotografias vivas e leituras de textos, tinham o propósito de, enquanto espaço de produção cartográfica, descobrir linhas, fluxos, pontos de tensão e encontros entre trabalhadores e usuários, sujeitos da pesquisa que, ao produzir juntos, iam se transformando em sujeitos do processo. 
Também, utilizamos do diário do cartógrafo, realizado por ocasião da observação assistemática, cujos registros tinham o propósito de conhecer e contribuir para a vivência no campo e o movimento de materialização das oficinas.

O campo do estudo foi uma unidade de Saúde da Família, localizada na periferia da cidade de Fortaleza/CE, Brasil. A escolha do local se relacionou pela diversidade existente: região com menor Índice de Desenvolvimento Humano (IDH), dificuldades de mobilidade urbana, indicadores elevados da violência e dificuldade de permanência de trabalhadores sem concurso nas equipes de saúde, à época da coleta.

Todavia, concentrava uma série de ações para população (Programa Saúde na Escola, Residência Médica e Multiprofissional em Saúde da Família, Núcleo de Apoio à Saúde da Família, quatro equipes completas de ESF e inversão de alguns indicadores primordiais ao campo da saúde (Taxa de Mortalidade Infantil, acompanhamento de pessoas com hipertensão e diabetes, tuberculose, hanseníase, pré-natal). Participaram do estudo 12 trabalhadores da unidade e quatro usuários. A produção dos dados aconteceu de agosto de 2010 a janeiro de 2011.

A análise do material, produzido na perspectiva rizomática, apropriou-se das diversas linguagens utilizadas no desenvolvimento da pesquisa. Após as transcrições das falas e leitura exaustiva dos textos (transcritos das oficinas), analisamos as imagens e percebemos o modo e a produção de cuidado de construção das narrativas de cada um (Amaral, Gentini, \& Amaral, 2018).

Estivemos atentos para encontrar as palavras de ordem, compreendidas como a relação de qualquer palavra ou enunciado com pressupostos implícitos, com atos de fala que se realizam no enunciado. A linguagem, que pode ser definida por um conjunto de palavras de ordem, comporta um discurso indireto, em que não há contornos, fronteiras, portanto, livre e capaz de revelar movimentos, tensões, forças e explicitação da multiplicidade de sentidos no processo enunciativo. Nesse percurso, identificamos o que denominamos produção cristalizada, na qual a produção do cuidado na ESF é antiprodução e as de linhas de fuga, movimentos de desterritorialização, com possibilidades de brotar a produção do cuidado na ESF (Deleuze, 2017).

\section{Resultados e Discussão}

\section{A produção do cuidado: entre linhas de fuga e cristalizações}

No plano da produção cristalizada, alguns enunciados revelam um sentido de despontencialização do grupo enquanto sujeito capaz de produzir o cuidado. Os trabalhadores, sobretudo, assumem um discurso da falta, da culpabilização e da recriminação, trazendo com eles a ideia de imobilização e fortalecendo uma aposta na impossibilidade pelos obstáculos que o macro e o microssocial apresentam como dados naturais, atribuindo ao cotidiano uma inércia, adiante da adinamia dos corpos presentes.

Para os trabalhadores, a falta de humanização apontada, nas oficinas, como algo que tem contribuído para os desencontros na dimensão do cuidado, foi expressa sob duas perspectivas: relacional e material.

Na relacional, o foco estabelecido tratou do aspecto da comunicação:

[...] concordo plenamente com o que já foi dito, que a gente precisa melhorar a comunicação e a humanização aqui (T5).

Ao refletir sobre a fala, temos explícito o discurso indireto que salta a partir das palavras de ordem - precisa melhorar a comunicação - levando a questionar sobre que comunicação acontece, identificando quem fala e o que comunica, obtendo respostas pela fala e pelos gestos. 
Desconstruir a palavra de ordem e construir novos sentidos é transitar de uma língua a outra e produzir outros enunciados. Quais agenciamentos são necessários para que os processos de comunicação produzam encontros?

Existe algo sendo comunicado no cotidiano dos serviços e para quem essa comunicação faz sentido, incluindo as diversas ideologias que percorrem os serviços de saúde. A subjetividade é plural e polifônica, isso apareceu de forma viva nos relatos (Bakhtin, 2013).

A segunda forma de expressão, da falta de humanização na perspectiva material, reforça ausências e faltas, sobretudo, de instrumentais necessários à prática dos cuidados acessados no cotidiano. O discurso da falta de humanização, muitas vezes, limita-se a uma questão procedimental (Ramos, Kattah, Miranda, Randow, \& Guerra, 2018).

\section{[...] falta estrutura física, falta uma série de coisas, mas a primeira coisa é a humanização, ele tocou bem na minha} ferida, porque, assim, o cliente ele chega na unidade de saúde procurando uma resposta, essa resposta pode ser positiva ou negativa, o importante é que ela saiba ser dada, ele quer uma resposta, e, muitas vezes, o cliente chega aqui na unidade e não tem essa resposta [...]. (T8)

Aí vem a questão da humanização que já foi colocada porque essa questão da humanização é relativa, têm pessoas que têm facilidade de trabalhar com o público, é natural da pessoa. E têm pessoas que têm dificuldade [...]. (T14)

Interferir nessa lógica pré-construída em interação passa por movimentos de desterritorialização, no que se fala e como fala, transitando por várias línguas a partir do lugar que ocupa ao expressar-se, mas, entendendo que há nesse sujeito um devir minoritário, uma potencialidade para desviar-se do modelo estabelecido, de linhas de segmentaridade duras, no sentido da construção da autonomia (Deleuze, 2017).

Nesse mapa do cuidado, é interessante perceber que os trabalhadores também relativizam essa questão da humanização como algo naturalizado, enraizado como terreno sólido, impassível de movimentação, impedindo o avançar na proposta de um modelo de atenção que dê conta das várias extensões existentes.

Existiram potências que poderíamos acessar nesse lugar para propor um novo modo de cuidar? É preciso caminhar apostando nas descobertas, na formulação de novos conceitos capazes de expressar o que se vive e se apreende desse cotidiano. Mas, para tanto, é necessário que o grupo se assuma como sujeito que, mesmo sob as condicionalidades que as relações micropolíticas requerem, consegue ver e entender as várias formas de expressão das potências, que não se reduzem a palavras, mas a um conjunto de enunciados do campo social, e a forma de conteúdo que não se reduz a uma coisa, mas a um estado de coisas complexo como formação de potência (Deleuze \& Guattari, 2017).

A fala a seguir expressa essas relações:

\section{[...] depende dos profissionais, eu acho que cada um fazendo a sua parte, vendo a questão humanitária que a saúde a} gente sabe que não é só doença, também é o acolhimento, é um sorriso, é um tratar bem, então, se a gente se colocar no lugar do outro, eu acho que a gente consegue melhorar a nossa saúde. (T10)

Outro sentido apreendido se visualiza pelo desencontro que se relaciona à religiosidade, tão evidente nesse território, com o poder de mascarar os papéis dos sujeitos presentes. Usuários e trabalhadores se desresponsabilizam ao propor que conflitos não sejam evidenciados e se minimizem como sujeitos, ao invocarem algo externo ao que acontece. O discurso da religiosidade não contribui para o avanço na solução dos problemas identificados, surge apenas para suprir "a carência generalizada", tão vivificada nos discursos presentes do grupo. 
O importante não é qualificar ou desqualificar essa ação discursiva, mas discutir como essa prática é assumida e os sujeitos envolvidos. Nas oficinas, trabalhadores e usuários se encontravam desempoderados, no sentido de propor ações de forma mais incisiva, com capacidade de suscitar no outro a necessidade da escuta e visualização de ações concretas. O poder é precisamente o elemento informal que passa entre as formas do saber (Deleuze, 2017, p. 122).

A construção de políticas públicas, que tomem como objeto a diversidade de sujeitos com suas diferenças, no SUS, fortalecem a ideia-prática de que é preciso cuidar de todas as pessoas:

\section{[...] Só os idosos não vim nesse sol já é uma ajuda [...]. (T2)}

[...] os agentes até querendo pedir o leite e mucilon, essas coisas nas casas para ajudar, uma família assim, superdifícil que eu contactei a assistente social, já foi lá para ver se consegue uma cesta básica... então, assim, lá tem tanta carência que eles querem que a gente esteja lá sabe pela mínima coisa...(T10)

Avançar da perspectiva caritativa, que evoca o assistencialismo para a dimensão de construção da cidadania e constitui um devir do trabalhador do serviço público, especificamente, o trabalhador da Estratégia Saúde da Família, em resgate ao padrão civilizatório dos territórios.

Problemas, como os apontados, revelam que são universais, afinal em quantos lugares ocorrem e têm desfechos semelhantes aos colocados? É importante pensar como objetivá-los no cotidiano e superá-los, pois, quanto mais absolutos e totalizantes eles parecerem, as soluções mais multiplamente locais devem constituir-se (Santos, 2013).

Cartografar e, no desenho dos mapas, identificar o que favorece e desfavorece a potência dos sujeitos, é fundamental para o diálogo, a partir dos textos que se produzem no cotidiano. Quais as palavras de ordem? Como subvertê-las ou dialogar a partir delas? Quais subjetividades se expressam nesse cotidiano do cuidado? Quais modelos de atenção estão em ação nesses territórios?

Interessante perceber que, muitas vezes, um único sujeito é portador de várias vozes e como elas reverberam a partir de uma expressão, de algo dito ou não dito, mas evocado. Nesse território, tão importante para a produção do cuidado, a produção cristalizada também se revela do existencial ao geográfico, com espaços e lugares diferenciados:

\section{[...] Eu me sentia ruim de entrar na escola, porque eu ia, porque eu tinha que ir [...] (T11).}

[...] Como pode ir lá para o Corrupião, no sol quente, e se ele tiver bem, ele vai conseguir ter uma relação legal, vai depender da disponibilidade do profissional. (T9)

O território tão pautado como algo do outro que pode desterritorializar-se, precisa ser experimentado com todos os relevos pelos sujeitos que nele se encontram. É, nesse sentido, que os corpos precisam resgatar a vibratilidade e a capacidade de acolher aquilo que é produzido no mundo da subjetividade (Rolnik, 1999), não pode ser negado, mas, muito pelo contrário, é preciso ser compartilhado, apesar da chamada para que se negue.

$\mathrm{O}$ que a trabalhadora quis expressar com esse sentimento ruim que the acomete ao chegar em um outro espaço físico, mas que também pode se configurar como lugar de produção de saúde? Um outro sentido em emergência, é necessário entender que transitar por esse(s) território(s) se configura ainda como ato político. E uma "experimentação ativa" que desse ponto emergiria uma linha de fuga ou de desterritorialização (Deleuze, 2017), componente ativo da política, e quem sabe a possibilidade de novas reconfigurações e até um ponto de encontro e composições no território. Aliás, de se permitir criá-los como consequência do encontro entre trabalhadores e usuários. 
Eu acho que a gente vai pouco até o território, então, assim, botei também poucos os pontinhos brancos no território, porque a gente vai pouco e chega pouco até as casas, conhece pouco o território onde a gente trabalha, uns mais outros menos, e tem algumas pessoas da população que nem chega até à unidade [...]. (T5)

O reconhecimento de que enquanto trabalhadores não conhecem esse território verbalizado, em uma das oficinas, também foi interessante, e o reforço à necessidade de conhecê-lo. Quem sabe, o início do movimento que gerará o processo de desterritorialização necessário para produção de subjetividades e consequente produção desejante no território da ESF.

Assim, é preciso um novo jeito de produzir vida, saúde nos territórios, promover rupturas e ouvir o que é vocalizado pelos usuários que, muitas vezes, reproduzem o que foi hegemonizado, o que está no campo das representações. Foi, assim, que entendemos a concepção de saúde que é adotada nessa ESF, na dimensão apontada por uma usuária e assumida por uma trabalhadora:

De vida e não é de vida porque posto de saúde a gente procura por doença né? (U2).

Um dos desafios em que precisamos pensar é sobre como fazer agenciamentos coletivos, investindo na autonomia e não na infantilização dos sujeitos (Silva et al., 2015). Como acessá-los, mesmo estando estes (trabalhadores e usuários) tão próximos-distantes? Por que os centros de saúde precisam se inscrever como territórios de doenças? Talvez precisássemos resgatar as ideias-força da ESF, conduzidas por Capistrano e sua equipe em Santos, em que seria imprescindível inventar, confrontar e socializar saberes (Lancetti, 2016).

Ao fazer o exercício de um novo campo do conhecimento para o 'Saúde da Família', propomos uma linha de fuga do modelo de "casinhas paralelas", onde cada trabalhador(a) está protegido no campo disciplinar, e encontrar as forças e fluxos que promoveriam uma reterritorialização, em que se pode construir um devir dos sujeitos implicados nessa estratégia de cuidado para construção de um campo comum, mas não somente isso, a análise de que o sujeito é capaz de produzir, a partir do desejo, projetos próprios de desenvolvimento (Schneider, Gomes, \& Ferraz, 2018; Sena et al., 2017).

É preciso superar esse modelo homogeneizador de que o "Doutor", ao atender alguém, é capaz de resolver os problemas, institui-se a lógica da medicalização social tão perversa e aprisionante. Foi muito importante ouvir o que os trabalhadores e usuários nos diziam para ver como se dá (o quê?) no dia a dia:

É muito difícil sair um paciente sem ser atendido, entendeu? Porque tem o acolhimento, às vezes, tem um profissional no médico: Dr., tem essa pessoa aqui, tem como resolver? (T2).

É ótimo, é bem cuidadoso eles com a gente, pergunta tudo, o que é que sente, se está tomando o remédio direitinho, passa remédio pra gente [...]. (U2).

Eu chego naquela portinha do Vicente. Será possível, Vicente, que eu vou morrer? (U4).

Os desencontros nos processos, de conceitos, concepções, práticas, ajudam-nos a refletir sobre os processos de medicalização e desvinculação tão presentes na prática de cuidado das unidades de saúde. A forma como as equipes trabalham o acolhimento é fundamental para que ele seja mais ou menos medicalizante. O cuidado continuado e a responsabilização pelo acompanhamento dos pacientes, que implica conhecê-los progressivamente, bem como seu contexto e a dinâmica psicossocial, econômica e cultural, é um poderoso mecanismo de aprendizado desmedicalizante (Sena et al., 2017, p.145). 
Além das questões apontadas, o reforço à organização do serviço, focada nos procedimentos, no desconhecimento do território, além da banalização, muitas vezes, de forma ingênua, mas assumida como polifonia de trabalhadores que assumem na unidade de saúde os lugares dos procedimentos, mas que também deveriam conhecer esse território da unidade em suas várias dimensões, e usuários que identificam nas ações praticadas jeitos de escapar da generalização, mas que não toma o cuidado como referência para tal:

Eu vou assim, fazer um curativo, da área [...] eu vou vacinar, fazer uma visita com a Dra. X., porque se eu sair daqui quebra as pernas [...] a Dra. X. vai fazer visita sempre me leva para poder ajudar. (T4)

Às vezes, eu ouço comentários de colegas, idosos, que devia ser assim: rapaz, é tão bom aqui, vamos tentar se esse grupo não acaba, já pensou você ir para o posto, uma ruma de gente para atender, e aqui a gente ter o atendimento [...]. (U3)

Habitar esse território rizomático que se compõe no cotidiano, eis o devir cartógrafo traçado, bem como acompanhar processos. É preciso que este compreenda desde já que há processos em curso, há vida e inacabamentos neste território (Freire, 2015; Kastrup \& Barros, 2009).

Assim, as palavras podem se revelar pela potencialidade que carregam a partir dos contextos em que foram expressas. Por isso, é preciso rachá-las, abri-las, como propõe Deleuze, para, desse modo, identificar as dobras realizadas no(s) território(s) da ESF e reconduzir-se a outros caminhos desterritorializando-se, rompendo com as cristalizações impostas pela via da ideologia que, majoritariamente, atravessa o cotidiano da produção do cuidado.

Eu comecei aqui, da realidade [...] eu como ACS, a realidade das nossas microáreas do risco 2 um aglomerado de casinhas, kitnetes, a doença já começa aqui [...]. (T10)

Aqui, nos deparamos com os encontros e as linhas de fuga da produção do cuidado na ESF ou com os movimentos e fluxos que propõem mudanças no que está, muitas vezes, no dia a dia do trabalho. Algumas expressões fizeram com que o grupo parasse para pensar no que era dito, de onde partir para cuidar dos sujeitos que habitam esse território? Que referenciais adotar? Sair daquilo que aparece tal qual algo dado como cristalizado e, literalmente, fazer a fuga ativamente, desterritorializando-se e encontrando as forças que operam para uma produção desejante.

A fala da agente comunitária de saúde e o desenho que ela fez foi capaz de expressar a potência que há em um encontro com o território. $\mathrm{O}$ agente comunitário de saúde, esse trabalhador híbrido na sua construção, enquanto sujeito de um processo de trabalho e, ao mesmo tempo, como membro dessa comunidade, revela que é nela que se devem buscar muitas das respostas para ação em saúde. Ressignificar modos de agir, pensar, olhar, viver, e criar a partir da realidade.

Esses momentos singulares provocaram no grupo afetações e isso, como parte do processo de produção da vida nos territórios, somente pode exprimir vulnerabilidades, aspectos das relações do cotidiano, que ainda precisam entrar em diálogo e encontrar superfícies capazes de as revelarem.

O território na ESF precisa ser visto em atividade. Por isso, a ideia que se torna fundamental ser acolhida, do território ativo, aquele que se expressa a partir dos dados, informações colhidas, muitas vezes, expressos nos indicadores determinados nos sistemas de informação do Ministério da Saúde, como também pelo vivido e sentido por aqueles que de um modo ou de outro atuam na ESF. Vale considerar que, ao ter uma ideia, assumimos como prática necessária com sua objetividade e a força que a carreia (Deleuze, 2017). 
Mais uma vez, a importância de entender os vários territórios que se cruzam no dia a dia e o que cada um (trabalhador e usuário) considera na organização do serviço para produção do cuidado, as relações que se estabelecem e as barreiras e facilidades para se chegar até aí.

Aqui, houve ativação de um coletivo de forças e o entendimento de que as diferenças não precisam ser negadas, muito pelo contrário, foi a partir delas que o grupo encontrou formas de expressar desejos até então não compartilhados no coletivo, realizações que fazem no cotidiano que podem modificar as relações existentes:

Cada um tem um jeito diferente, tem problemas diferentes, tem coisas que eu nem conhecia, só conversando, problemas de saúde, que se eu tivesse ficado parada só no meu cantinho, eu não ia conhecer, então, às vezes, precisa do outro para chegar, para que tenha um grupo, entendeu? (T2)

Também nos deparamos com outra questão, em relação ao lugar de quem fala, de quem diz, que forças operam naquele momento, quem escuta quem fala? Que palavras de ordem estão sendo expressas e como elas se objetivam no cotidiano?

A fala acima, proferida por uma trabalhadora da unidade, que opera na recepção da unidade de saúde, também, é capaz de dizer o quanto de agenciamentos ainda precisam ser operados nesse campo micropolítico, as relações ainda são individualizadas e a promoção de agenciamentos coletivos precisa ser realizada, há espaços opacos que precisam de cor, de uma assimetria.

Essa falta de simetria carrega potência, pois, ao se revelar, pode criar processos que tenham a capacidade de produzir encontros a partir das subjetivações no coletivo (Deleuze, 2018). Essa diferença pode produzir processos de desterritorialização e consequente reterritorialização, foi um corte produzido em uma das linhas do rizoma, que pode conectar-se a outro com sua heterogeneidade (Santos et al., 2018).

\section{[...] a gente trabalha muito em parceria com o CRAS, é tanto que o meu grupo de idosos é o mesmo grupo de idosos do CRAS, porque praticamente são os mesmos idosos dessa área, eu digo, então, a gente não vai fazer um duplo trabalho que é isso que o SUS propõe [...]. (T12)}

É interessante olhar as linhas de fuga que vão sendo cruzadas, feitas e reveladas, o que, em algum momento, revelouse como algo que é capaz de retirar potência, aparece em polifonia expressa por outros sujeitos no mesmo grupo, revelando mais um encontro possível no território e, mais que isso, com a vivência articulada entre setores distintos, a intersetorialidade é desenvolvida em alguns lugares daquele território, aparecendo no aspecto singular, mas como fortaleza para o trabalho de ambas as equipes, a de saúde e assistência social, o mais interessante com os mesmos sujeitos sendo trabalhados. Trata-se, portanto, de encontrar o que desperte o corpo vibrátil, funcionando como um fator de afetivação da existência (Rolnik, 1987).

Ficou muito claro na pesquisa que há muito que se cuidar, dentro e fora da ESF, mas que essa capacidade de criação, que todos têm, é algo que pode ser acessado para que a micropolítica do cuidado seja capaz de se efetivar a partir das linhas de fuga que confluem para zonas de platôs, com intensidade.

É preciso estar atento para os acontecimentos que mediam processos e geram fluxos novos, e como estes desembocam na criação, atividade permanente que os sujeitos implicados com a prática do cuidado precisam assumir, criadores, preceptores de afetos, de sentidos, de subjetividades, de conceitos para uma realidade que também se modifica a partir do encontro de outros corpos. Há todo um plano de imanência com suas multiplicidades, singularidades, onde as intensidades variam (Deleuze, 2017; Santos et al., 2018). 
Foi muito interessante percebermos o quanto esses encontros possibilitaram avançar na tecitura de relações e que outras questões protagonizam pensamentos no campo da produção do processo saúde-doença, outros temas para além da doença, tão focalizada em determinados momentos das oficinas vivenciadas, também circulam, foi assim quanto à questão da cidadania, como expressou a trabalhadora:

[...] Eu acho que a questão do trabalho é fundamental para dar dignidade às pessoas, ter uma perspectiva de vida melhor [...] Mais do que o assistencialismo que a gente vê [...]. (T12)

É preciso que tenhamos clareza de que a centralidade na atenção ao usuário do serviço não precisa estar focada na protocolização (Costa, Marques, Ceccim, \& Silva, 2019; Seixas et al., 2019) a que trabalhadores estão, muitas vezes, sendo cobrados, mas na implicação que estes vão assumir quando veem a capacidade que estes têm de lidar com a complexidade de relações que a vida nos propicia. Por isso, urge compreender os pensamentos e expressões que cada um traz consigo, revelando autonomias e singularidades.

As linhas de fuga produzidas pelos sujeitos davam brechas para apontar caminhos eminentemente desejados e possíveis. Entre tantos enunciados coletivos, pela politicidade que cada um sempre carrega, e pelo despertar do corpo vibrátil que pelo potencial de afetar-se aos encontros, produzindo zonas de intensidades com produção de novos conceitos, viu-se que existem potencialidades para efetivarem-se novas práticas de cuidado, comprometidas com a produção da saúde, que se referenda pela multiplicidade de desejos em produção no cotidiano dos territórios da atenção.

\section{Conclusão}

Desta forma concluímos que a cartografia, neste estudo, apresentou relevos em multiplicidades, pela polifonia expressa nas várias vozes (trabalhadores que ocupam posições diferentes no mundo do trabalho e usuários que articulam diferentes modos de viver, todos com condições singulares de existência e audibilidades) e polissemia de sentidos que, enquanto forças, podem desterritorializar-se para garantir a produção do cuidado na ESF. Assim, analisar os espaços onde a produção se encontra cristalizada, quando o discurso da falta é capaz de imobilizar sujeitos (trabalhadores e usuários) e operam despotencializando encontros, foi fundamental.

A burocratização das ações do cuidado, regulada e assumida enquanto normas técnicas, destituídas de vínculo, sem garantir os processos de autonomização, retira do trabalhador e do usuário a potência da criação, necessários ao estabelecimento de relações. Há um imaginário que se fortalece pela solidificação da subjetividade capitalística que captura os sujeitos e os modela para se exercer o controle da(s) vida(s).

A diversidade de linguagens possibilitou as manifestações desses sujeitos, em que visualizamos os arranjos existentes e quem, de fato, tem falado, que enunciados coletivos têm sido produzidos por uma formação, muitas vezes, distante da realidade, cada vez mais focada na lógica mecanicista, individualista, medicalizante e produzida capitalisticamente, portanto, mais distante da produção do cuidado que, para acontecer, necessita se transversalizar nas relações que cada um pode estabelecer com o outro (trabalhador e/ou usuário).

O grupo também revelou, nas linhas construídas, traçadas nas oficinas, ou mesmo no que reverberava daqueles encontros, movimentos desterritorializantes, quando tudo parecia certo e dado uma microrrevolução, o devir minoritário era expresso e, nessa metamorfose, revelavam-se potencialidades e começaram a construir as condições de possibilidade para transformações, autonomamente, conscientes de si, destacando, inclusive, a potencialidade revolucionária das palavras de ordem. 
O estudo, também apontou que a cartografia, enquanto processo metodológico, produz rupturas no modo de fazer pesquisa no campo da enfermagem. Nosso estudo aponta que a ousadia de produzir cartografias da ESF foi possível pelo engajamento e pela capacidade crítica de pesquisadores da enfermagem assumir novas formas de fazer pesquisa, rupturas inclusive no campo epistemológico. Para a enfermagem, traz fortes contribuições, uma vez que, no cenário da APS, o enfermeiro se configura como força motriz nas relações sociais que se estabelecem. Esperamos inspirar outros enfermeiros a adentrar no campo da cartografia.

\section{Referências}

Agonigi, R. C., Carvalho, S. M., Freire, M. A. M., \& Gonçalves, L. F. (2018). A produção do cuidado no cotidiano das Equipes de Saúde da Família. Rev Bras Enferm., 71(Suppl 6), 2659-2665. https://doi.org/10.1590/0034-7167-2017-0595.

Amaral, A. L. M., Gentini, A. G. M., \& Amaral, R. A. (2018). Grupo como dispositivo: a microintervenção ecosófica nos processos de formação em educação ambiental. Educ Pesqu., 44, e170967. https://doi.org/10.1590/s1678-4634201844170967

Arruda, C. A. M., \& Bosi, M. L. M. (2017). User's satisfaction of primary health care: a qualitative study in the Northeast of Brazil. Interface (Botucatu), 21(61), 321-32. https://doi.org/10.1590/1807-57622015.0479

Bakhtin, M. (2003). Estética da criação verbal. (4a ed.), Martins Fontes.

Brasil. Ministério da Saúde. (2017). Portaria n 2.436 de 21 de setembro de 2017. Aprova a política nacional de atenção básica, estabelecendo a revisão de diretrizes para a organização da atenção básica no âmbito do Sistema Único de Saúde (SUS). Brasília: Ministério da Saúde.

Costa, C. K., Marques, R., Ceccim, R., \& Silva, K. (2019). Educação permanente em saúde e modelo assistencial: correlações no cotidiano do serviço na Atenção Primária a Saúde. APS, 1(2), 132-140. https://doi.org/10.14295/aps.v1i2.28

Deleuze, G. (2017). Conversações. Editora 34.

Deleuze, G. (2018). Diferença e repetição. Paz e terra.

Deleuze, G. \& Guattari, F. (2017). Introdução: rizoma. In: Deleuze, G., \& Guattari, F. Mil platôs. capitalismo e esquizofrenia. Editora 34.

Ferla, A. A. (2017). Trabalho em saúde, corpo e subjetivação capitalística. Interface (Botucatu), 21(63), 1024-1026. https://doi.org/10.1590/180757622017.0323.

Freire, P. (2015). Pedagogia da autonomia: saberes necessários à prática educativa. Paz e Terra.

Giovanella, L., Bousquat, A., Schenkman, S. Almeida, P. F., Sardinha, L. M. V. \& Vieira, M. L. F. P. (2021). Cobertura da Estratégia Saúde da Família no Brasil: o que nos mostram as Pesquisas Nacionais de Saúde 2013 e 2019. Ciência \& Saúde Coletiva. 26, (suppl 1). 2543-2556. https://doi.org/10.1590/141381232021266.1 .43952020 .

Guattari, F., \& Rolnik, S. (2011). Micropolítica: cartografias do desejo. (12a ed.), Vozes.

Kastrup, V., \& Barros, R. B. (2009). Movimentos-funções do dispositivo na prática da cartografia. In: Franco, T.B., Andrade, C.S., \& Ferreira, V.S.C. (orgs.). A produção subjetiva do cuidado: cartografias da estratégia saúde da família.: Hucitec.

Lancetti, A. (2016). Clínica peripatética. (9a ed.), Hucitec.

Ramos, E. A., Kattah, J. A. R., Miranda, L. M., Randow, R., \& Guerra, V. A. (2018). Humanização na Atenção Primária à Saúde. Rev Med Minas Gerais, 28(Supl 5), e-S280522. http://rmmg.org/artigo/detalhes/2454.

Lemos, R. A. (2018). Conferências Nacionais de Saúde e a construção do Sistema Único de Saúde - SUS: Uma revisão. Rev. APS, 21(4). https://periodicos.ufjf.br/index.php/aps/article/view/15635.

Ramos, E. A., Kattah, J. A. R., Miranda, L. M., Randow, R., \& Guerra, V. A. (2018). Humanização na Atenção Primária à Saúde. Rev Med Minas Gerais, 28(Supl 5), e-S280522. http://rmmg.org/artigo/detalhes/2454.

Rolnik, S. (1987). Cartografia sentimental da América: produção do desejo na era da cultura industrial. São Paulo: Pontifícia Universidade Católica de São Paulo.

Rolnik, S. (1999). Novas figuras do caos: mutações da sociedade contemporânea. In: Santaella, L., \& Vieira, J.A. Caos e ordem na filosofia e nas ciências. São Paulo: Face e FAPESP.

Santos, A. R., Carvalho, M. F., Santos, R. M. M., Anjos, S. D. S., \& Andrade, C. S. (2018). A produção do cuidado na atenção primária à saúde: uma compreensão teórico-filosófica. Cienc Cuid Saúde, 17(3). https://doi.org/10.4025/cienccuidsaude.v17i3.39945

Santos, B. S. (2013). Pela mão de Alice: o social e o político na pós-modernidade. (9a ed.), Cortez.

Santos, D. S., Mishima, S. M., \& Merhy, E. E. (2018). Processo de trabalho na Estratégia de Saúde da Família: potencialidades da subjetividade do cuidado para reconfiguração do modelo de atenção. Ciênc Saúde Coletiva, 23(3), 861-870. https://doi.org/1 0.1590/1413-81232018233.03102016. 
Research, Society and Development, v. 10, n. 8, e57410817552, 2021

(CC BY 4.0) | ISSN 2525-3409 | DOI: http://dx.doi.org/10.33448/rsd-v10i8.17552

Santos, E. S. \& Ceccon, R. F. (2021). O olhar do Flâneur: uma cartografia da Atenção Básica à Saúde. Interface - Comunicação, Saúde, Educação [online], 25, e200026. https://doi.org/10.1590/interface.200026.

Schneider, L. R., Gomes, R. P., \& Ferraz, L. (2018). A prática baseada em evidência no contexto da Atenção Primária à Saúde. Saúde Debate, 42(118). https://doi.org/10.1590/0103-1104201811804

Seixas, C. T., Baduy, R. S., Cruz, K. T., Bortoletto, M. S. S., Slomp Junior, H. \& Merhy, E. E. (2019). O vínculo como potência para a produção do cuidado em saúde: o que usuários-guia nos ensinam. Interface (Botucatu). 23, e170627. https://doi.org/10.1590/Interface.170627

Sena, R. R., Grillo, M. J. C., Pereira, L. A., Belga, S. M. M. F., França, B. D., \& Freitas, C. P. (2017). Educação permanente nos serviços de saúde: atividades educativas desenvolvidas no estado de Minas Gerais, Brasil. Rev Gaúcha Enferm., 38(2), e64031. https://doi.org/10.1590/1983-1447.2017.02.64031

Silva, A. M. P., \& Rojas, F. L. M. (2016). Cartografia em saúde: mapeando as experiências, desafios e possibilidades no cotidiano do trabalho. Rev Cienc Est Acad Med., 5, 30-41. https://periodicos.unemat.br/index.php/revistamedicina/article/view/927/1408

Silva, M. R. F., Silveira, L. C., Pontes, R. J. S., \& Vieira, A. N. (2015). Care beyond health: mapping bonding, autonomy and emotional territory in family health. Rev Min Enferm., 19(1), 255-259. https://doi.org/10.5935/1415-2762.20150020 